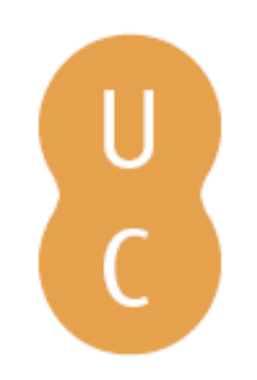

\title{
pombalina
}

\section{Mértola: um espaço lendário e místico}

Autor(es): $\quad$ Nunes, Natália Maria Lopes

Publicado por: Associação Portuguesa de Estudos Clássicos; Centro de Estudos

Clássicos e Humanísticos

URL

persistente: URI:http://hdl.handle.net/10316.2/31555

DOI: $\quad$ DOI:http://dx.doi.org/10.14195/978-989-8281-69-2_14

Accessed : $\quad$ 26-Apr-2023 12:15:23

A navegação consulta e descarregamento dos títulos inseridos nas Bibliotecas Digitais UC Digitalis, UC Pombalina e UC Impactum, pressupõem a aceitação plena e sem reservas dos Termos e Condições de Uso destas Bibliotecas Digitais, disponíveis em https://digitalis.uc.pt/pt-pt/termos.

Conforme exposto nos referidos Termos e Condições de Uso, o descarregamento de títulos de acesso restrito requer uma licença válida de autorização devendo o utilizador aceder ao(s) documento(s) a partir de um endereço de IP da instituição detentora da supramencionada licença.

Ao utilizador é apenas permitido o descarregamento para uso pessoal, pelo que o emprego do(s) título(s) descarregado(s) para outro fim, designadamente comercial, carece de autorização do respetivo autor ou editor da obra.

Na medida em que todas as obras da UC Digitalis se encontram protegidas pelo Código do Direito de Autor e Direitos Conexos e demais legislação aplicável, toda a cópia, parcial ou total, deste documento, nos casos em que é legalmente admitida, deverá conter ou fazer-se acompanhar por este aviso.

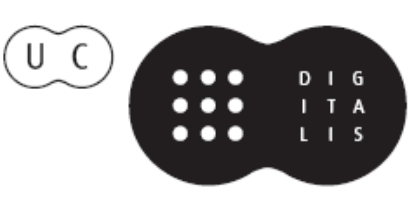




\section{Espaços e Paisagens}

Antiguidade Clássica

e Heranças Contemporâneas

Vol. III

Francisco Oliveira, Jorge Oliveira e Manuel Patrício

IMPRENSA DA UNIVERSIDADE DE COIMBRA 


\title{
MÉRTOLA - UM ESPAÇO LENDÁRIO E MÍSTICO
}

\author{
Natália Maria Lopes Nunes \\ Universidade Nova de Lisboa \\ Faculdade de Ciências Sociais e Humanas \\ IELT/CEIL
}

\section{Résumé}

La beauté du paysage naturel, près du Guadiana (le fleuve de la déesse), est un espace légendaire et mystique depuis longtemps. Plusieurs découvertes archéologiques (quelques unes exposées au Musée de la Ville et d'autres au Musée National d'Archéologie) sont les témoins d'un passé historique très riche, surtout sous les domaines romain et arabe. De la période romaine, il y a des inscriptions dediées à la déesse Atégina (ou selon quelques auteurs, dediées à la déesse Prosérpine), avec l'épithète Dea Sancta, la sculpture de la tête de la déesse Cybèle et du dieu Dionysos, des amulettes phalliques et quelques monuments funéraires; de la période islamique, il y en a aussi plusieurs vestiges (un quartier, des objets en or, matériel de cuisine, une nécropole, l'église qui a été une mosquée) et c'est la ville du soufi Al-Mîrtulî; de la période chrétienne, il y en a des chapelles et des églises, surtout dediées à la Vierge et aux saints, comme par exemple, S. Barão. Cependant, les légendes de la région, comme l'origine du nom Mértola, «La Ciseaux de la Mauresque» et la légende de S. Barão ont fait de Mértola un espace légendaire e mystique. Mírtilis, Mirtolah, Mértola - région de Romains, d'Arabes et de Chrétiens - a été un espace sacré et partagé par plusieurs cultures, lieu où on a vénéré les déesses Atégina (ou Prosérpine, selon d'autres opinions) et Cybèle, le dieu Dionysos et où a vécu le poète soufi Al-Mîrtulî et le saint chrétien S. Barão, les exemples plus importants de l'espace légendaire et mystique de la ville.

Mots clefs: Al-Mîrtulî, découvertes archéologiques, Grande Déesse, légendes, Mauresque enchantée, Mértola, S. Barão, Serpent, Soufisme.

Palavras-chave: achados arqueológicos, Al-Mîrtulî, Grande Deusa, lendas, Mértola, mouras encantadas, S. Barão, serpente, sufismo.

Mértola, situada no distrito de Beja, foi palco da presença de diversos povos que remontam ao Período Neolítico. No entanto, e de acordo com a temática do presente volume, salientamos as presenças romana, árabe e cristã.

Mértola, com a beleza da paisagem natural, tendo a seus pés o Guadiana (o rio da deusa), tornou-se um espaço lendário e místico ao longo dos séculos. A sua localização, tendo ainda em conta a navegabilidade do rio, exerceu uma forte influência na região. Se a riqueza dos solos era pobre, a do subsolo era muito rica, situação que se revela desde a Antiguidade, integrando a vila na faixa Piritosa Ibérica, destacando-se a exploração de chumbo, cobre, prata 
e ouro. A exploração mineira das Minas de S. Domingos é exemplo dessa ancestralidade já desenvolvida por fenícios e cartagineses.

No período romano julga-se que Mértola fosse um ponto estratégico nas relações com o Mediterrâneo. Segundo o arqueólogo Carlos Fabião, a romanização ter-se-ia iniciado bastante cedo pelo facto de o local ser um porto de entrada dos exércitos romanos.

No que diz respeito à toponímia, segundo alguns autores e geógrafos da Antiguidade, como Estrabão e Plínio, Mértola é a antiga Myrtilis, nome que, segundo Estácio da Veiga, poderia ter origem fenícia, partindo de Myr que significa nova, seguida de Tyri que significa Tiro. Esta relação remete para a conquista de Tiro em 333/332 a.C. por Alexandre Magno, rei da Macedónia; o autor refere ainda a origem grega do nome, partindo do nome Myrtilo, filho de Mercúrio, ou da origem latina, a partir de Myrtus. Contudo, segundo o autor, estas interpretações etimológicas derivariam mais do seu carácter lendário, do que dos aspectos linguísticos, daí as interpretações não serem, por vezes, consideradas fiáveis. A lenda de "Serpínia, a Princesa Feliz" faz alusão à fundação de Mértola, atribuindo o nome ao filho de Mercúrio com a deusa Mirto:

«Cófilas, Rei dos Túrdulos, fez aliança com os chefes Fenícios e, naquele porto, construíram uma cidade a que deram o nome de Mirtilis, em honra da Deusa Mirto, sua mãe que o teve de Mercúrio. [...] Cófilas e Polípio firmaram um tratado de amizade e mútua defesa. Além do casamento com Serpínia estipulou-se que os fenícios estabelecessem uma feitoria comercial em Mirtilis. Nesse porto ficariam sempre equipados com homens e material dois navios fenicios que ao mesmo tempo patrulhariam o litoral da Turdetânia, pelo menos enquanto o perigo não passasse. Em caso de guerra com qualquer adversário cada um dos contratantes prestaria mútuo auxilio.

Com medo de novos ataques a princesa mandou aviso ao pai, que estava em Mirtilis, que hoje se chama Mértola [...]» ${ }^{1}$.

No entanto, como não se comprovou a existência de uma deusa com o nome de Mirto, a mesma foi associada à deusa Afrodite, a deusa da beleza e do amor, através da planta que a simboliza, o mirto.

Ainda do período romano, para além de alguns monumentos funerários dos séculos II-III d.C., de entre eles uma tabela rectangular com um epitáfio a Publicia Lucina e uma ara funerária de Lucius Liburnius Maternus (peças que se encontram expostas no Museu Nacional de Arqueologia), foram encontradas algumas epígrafes que estabelecem uma relação entre o culto da deusa préromana Atégina e da deusa Prosérpina, tal como se verifica na inscrição «Dea

\footnotetext{
${ }^{1}$ Cabral, in http://joraga.net/mertola/pags/20lendas1.htm\#serpinea 165-167.
} 
sancta Ataecina Turibrigensis Proserpina» (em Mérida, Badajoz). No entanto, como afirma Juan Manuel Abascal Palazón:

«A própria evidência epigráfica mostra que não se realizou uma autêntica hypostasis e que ambos os cultos possuem áreas especificas de desenvolvimento. Haveria agora que trazer à colação as epígrafes que mencionam só dea sancta e que afastámos como evidências de Ataecina: cinco procedem de Mérida, Mértola, Beja e Serpa, ou seja, sobre a latitude ou a sul da latitude de Mérida [...] é fácil de deduzir que estas tácitas alusões a uma dea sancta devem pois referir-se a Proserpina e não a Ataecina»².

Em Mértola foi também encontrada uma cabeça da deusa Cíbele e do deus Dioniso ${ }^{3}$. Além disso, e talvez em correlação com o culto dionisíaco, foi encontrado um amuleto fálico na Mina de S. Domingos datado do período pré-romano, um phallus cum scroto pubeque ${ }^{4}$. Desde a Pré-História que o uso de amuletos ou de talismãs era uma prática comum. Estes objectos sagrados reflectiam as crenças, detinham poderes mágicos e tinham como principal função a protecção do ser humano contra os males que o poderiam prejudicar.

O período da ocupação islâmica também legou a Mértola um património muito importante. A Espanha muçulmana tornara-se independente com os Abássidas, tendo Córdova como grande centro da cultura islâmica. No entanto, as influências dessa cultura expandiram-se também à zona correspondente a Portugal, embora se encontrassem nesses territórios outras tradições ancestrais. Como afirma Dominique Sourdel, partindo dos estudos de E. Lévi-Provençal:

«Nos séculos X e XI, a Andaluzia, onde as tradições sírias permaneciam vivas, conheceu uma cultura requintada, a qual não só rivalizou com o sucesso com a sua iniciadora oriental, à qual se mantivera fielmente ligada, mas também «se soube impor fora dos limites muçulmanos e determinou em parte a evolução do pensamento e do saber europeus dos séculos antes do Renascimento» (E. Lévi-Provençal) ».

Certamente, tal como aconteceu em outras regiões, Mértola também presenciou a sobreposição de culturas e de religiões diferentes ao longo das épocas, desde o Período Neolítico. A relação da vila com o Mediterrâneo, estabelecida já no período pré-romano, tornou a região um centro de contacto entre o Ocidente e o Oriente. A nível arqueológico existem diversos elementos: vestígios de um bairro, utensílios de cozinha, objectos em ouro (anéis, brincos,

\footnotetext{
${ }^{2}$ Palazón 200256.

${ }^{3}$ Cf. Souza 2002 247-250.

${ }^{4}$ Ponte 2002 269-272.

${ }^{5}$ Lévi-Provençal, apud Sourdel 199132.
} 
fivelas, etc.), a necrópole e a Igreja Matriz de Mértola, outrora mesquita (como atestam alguns vestígios).

Porém, desta época sobreviveram em Portugal muitas lendas de mouras. "A Tesourinha da Moura" é uma dessas lendas que estabelecem a ponte entre os primitivos cultos de Mértola que sobreviveram na lenda. Segundo a lenda:

«Ali para os lados de Mértola, aconteceu, certa vez, um caso fantástico e temeroso provocado por uma moura encantada.

Vinha um homem do amanho do campo, de enxada ao ombro, quando ao passar pelo sitio da Mortilhera viu uma cobra que da cintura para cima tinha corpo de mulher. A cobra, que era uma moura encantada, meteu-se a conversar com o homem, e o homem cheio de medo, a suar e a limpar o suor com o lenço.

A moura foi perguntando ao homem como lhe corria a vida, que tal as colheitas, se a seara era dele ou se tinha patrão, e muitas outras coisas com as quais talvez viesse a entreter-se nos longos serões que de Inverno era obrigada a passar sozinha debaixo da terra. Quando acabou de saber tudo o que a interessava, a moura estendeu ao homem um capacho com figos secos, que estava a seu lado, dizendo-lhe que tirasse quantos quisesse.

O homem, que durante todo o tempo da conversa suara frio, de medo e nervos, tirou meia dúzia de figos e meteu-os na algibeira do colete. Despediu-se da cobra com alguns salamaleques e partiu aliviado e desejoso de se ver bem longe dali.

Ao chegar a casa contou à mulher o que lhe acontecera e por fim, quando ia a tirar os figos do bolso do colete, encontrou no lugar deles seis moedas de ouro. A mulher desatou logo a ralhar com ele:

—Ó homem, pois então a moura dá-te figos que são ouro e tu só trazes isto?! Valha-te Deus, que estás mas é a ficar taralhouco! Vai mas é buscar o resto, antes que a cobra volte à cova, vai depressa, ouviste?!

O homem, que não sabia bem se havia de temer mais o bicho ou a mulher, lá foi, dizendo mal à sua vida. E quando passou pela cobra, disse-lhe, para que ela não desconfiasse:

- Adeus, senhora moura! Vou outra vez ao campo, que me esqueci de uma coisa!

Mas a moura sabia tudo:

- Não vais, não! Não te esqueceste de nada, o que tu querias era mais figos, mas já não há! Olha, leva daqui qualquer coisa que te sirva. 
E estendeu ao homem o seu açafate da costura, donde ele sacou uma tesourinha com cabos de ouro e pedras preciosas. Partiu e a moura ficou a dizer-lhe adeus com um estranho sorriso.

A caminho de casa, o homem, que ia distraído com os seus pensamentos, escorregou à beira de uma ladeira, caiu, espetou a tesoura no peito e morreu.

Assim acontece quando os encontros com mouras não são mantidos em segredo!» ${ }^{6}$

Desta lenda destacamos a personagem feminina da moura encantada, metade mulher, metade serpente, articulando-a com os vestígios arqueológicos da região, nomeadamente com o culto de Cíbele, Prosérpina e Dioniso. A ancestralidade da serpente como animal sagrado, ctónico e aquático tem raízes indo-europeias. Por outro lado, ela é ainda uma das representações das grandes deusas, das deusas-mães ligadas à fertilidade e à regeneração que, no Cristianismo, sobreviveram nas diversas lendas e na figura da Virgem Maria. Citando Ria Lemaire:

"Associada à fertilidade, a Serpente-Deusa é imaginada quase sempre boa, benéfica, generosa; os ritos que lhe são dedicados celebram a sua soberania sobre a vida, a fertilidade, a felicidade dos seres humanos, apelam para os seus poderes curativos, lenitivos e divinatórios»? ${ }^{7}$.

O imaginário da mulher serpente encontra-se no mito de Melusina, também ela uma mulher serpente, mito ancestral, remetendo para a mulher com um carácter sobrenatural. Assim, a moura da lenda é uma sobrevivência desse imaginário. Saliente-se ainda o facto de a serpente ser uma das representações da deusa Cíbele, a Grande Deusa, mãe dos deuses que, como vimos pelos vestígios arqueológicos, também foi venerada em Mértola, articulando-se ainda com Dioniso, também cultuado nesta região e que tem uma estreita relação com o culto da respectiva deusa, como se pode verificar n'As Bacantes de Eurípides. Por outro lado, e estreitamente ligado aos cultos de fertilidade, existe ainda o amuleto fálico encontrado nas Minas de S. Domingos. Além disso, as epígrafes que ligam as deusas Atégina a Prosérpina (tenha sido um ou outro culto) relacionam-se com a fecundidade e com a regeneração. Assim, e citando Jean Chevalier e Alain Gheerbrant, a serpente será, simbolicamente, «ao mesmo tempo útero e falo». ${ }^{8}$

Esta ancestralidade simbólica ligada à serpente subsistiu durante séculos, encontrando-se, actualmente nas lendas, como é o exemplo d' "A Tesourinha da Moura". A figura feminina desta lenda, a moura, na continuidade do poder sagrado das Grandes Deusas, é doadora da vida e da morte, sendo benéfica

\footnotetext{
${ }^{6}$ Frazão s/d 89-91.

${ }^{7}$ Lemaire 1999-2001 85.

${ }^{8}$ Chevalier e Gheerbrant 1994600.
} 
ou maléfica, tecendo o destino do homem. O poder da mulher serpente sobre o destino está bem explícito na lenda. Neste sentido, e partindo dos vestígios arqueológicos encontrados em Mértola e em todo o seu concelho, as lendas serão uma sobrevivência de um fundo mítico ligado a antigos cultos da região. A moura é, então, uma hierofania, uma manifestação do sagrado e da vida. Como afirmam os autores anteriormente citados:

«Todas as serpentes possiveis formam juntas uma única multiplicidade primordial, una, indivisivel [...] ligado à ideia da vida; em árabe, a serpente é el-hayyah e a vida é el-hayat (GUES, 159) [...]. Num plano mais precisamente cosmogónico - e que, no Sufismo, se torna a base de uma mística -,é a dilaceração da unicidade primeira, dois em um, que se divide nos seus dois componentes para permitir a ordem humana [...]» ${ }^{9}$.

Para além de todo este imaginário lendário ligado às mouras, não poderemos deixar de referir outro aspecto de extrema relevância e que tornou Mértola um espaço místico - o Sufismo. Esta corrente teve um papel importante na Península Ibérica, nomeadamente em Portugal e, para além de influenciar a literatura da época, teve uma função preponderante na espiritualidade. $\mathrm{Na}$ Península Ibérica, desenvolveu-se sobretudo a partir dos séculos IX e X com Ibn Masarra, de Córdova. Um dos grandes poetas sufis foi Ibn Arabi (séculos XII-XIII). O seu Tratado do Amor influenciou a mística medieval, tendo subjacente a concepção platónica do Belo.

Um dos mestres de Ibn Arabi foi o sufi de Mértola, Al-Mîrtulî (século XIII). Este místico de Mértola passou uma vida de ascese baseada na meditação e no recolhimento. Devido à sua relevância, não poderemos deixar de apresentar dois dos seus poemas, publicados em $O$ meu Coração é Árabe de Adalberto Alves:

\author{
«quanto do que intento que não faço \\ e como, sem fio, eu vagueio. \\ falo à minha alma, ela não escuta \\ critico tudo e inda assim não creio. \\ a quanto do que fica sempre por fazer \\ eu direi «mais tarde!» e tudo tarda. \\ me atraso confiado em longa vida: \\ cedo vem a morte que nunca se guarda. \\ todos os dias ela, feita pregoeira, \\ diz «alto!» a muitos dos que vão passando. \\ setenta e nove anos já voaram. \\ que mais estarei eu ainda esperando?» ${ }^{10}$
}

\footnotetext{
${ }^{9}$ Idem 1994596.

${ }^{10}$ Alves 1999234.
} 


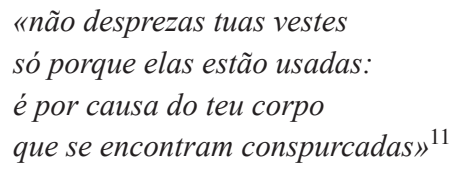

Posteriormente, o Cristianismo, através da devoção da Virgem, continuou o culto das deusas Cíbele e Prosérpina sob os mais diversos nomes, de entre eles: Nossa Senhora da Anunciação, Nossa Senhora das Neves, Nossa Senhora da Conceição, Nossa Senhora do Carmo, Nossa Senhora da Graça, Nossa Senhora da Cabeça, Nossa Senhora dos Remédios, etc. Citando Joaquim Manuel Ferreira Boiça:

«Na religiosidade popular, a Virgem é a «Senhora dos mil nomes», título que expressa bem a multiplicidade das suas invocações e que deixa perceber a dimensão plural do culto que lhe é prestado. São mil os nomes porque são incontáveis as suas associações devotivas: à maternidade divina e aos mistérios da Paixão e Morte de Cristo; sentimentos e estados de alma; a lugares e elementos da natureza; a crenças intemporais do inconsciente colectivo; a necessidades quotidianas dos homens e do seu porvir; a paixões místicas; a festividades da vivência rural e urbana, etc.» ${ }^{12}$.

Quanto ao culto dos santos, eles foram os sucessores dos deuses pagãos, atingindo o seu carácter de santidade um elevado nível místico, aproximandoos da figura de Cristo. Alguns deles foram de culto local ou regional. Como tal, não poderemos deixar de fazer alusão a um santo considerado local e que, pela sua vida ascética, se aproxima do sufi de Mértola Al-Mîrtulî, S. Barão. Este santo, pelas suas características, reflecte a continuidade dos cultos ligados à fertilidade, cura e regeneração, à semelhança das divindades outrora cultuadas em Mértola.

Alguns cronistas, ao narrarem a vida de S. Barão, fazem dele um santo local que, para além de se articular com os cultos ancestrais, também tem semelhanças com a vida do sufi Al-Mîrtulî. Segundo Frei Leão de S. Tomás, é narrado o seguinte:

«Legoa e meya deste sitio do Mosteyro sobredito do Salvador para Mertola esta huma ermida de S. Barão em huma áspera serra, a quem ele dá o nome, e não longe da ermida se vê a cova, a que chamão a Cella, na qual dizem que vivia este santo vida solitária sostendo-se das ervas que cultivava e regava com a agua de huma fonte que no mesmo sitio nasce. A devoção deste santo he muy antiga em Mertola aonde ha muitos homens deste nome, porque os casados o têm por advogado seu, para thes alcançar fruto de bênção». ${ }^{13}$

\footnotetext{
${ }^{11}$ Idem 237.

${ }^{12}$ Boiça 1998141.

${ }^{13} \mathrm{~S}$. Tomás 1644438 .
} 
Os milagres do santo foram diversos. Para além dos milagres climatéricos ligados aos pedidos de chuva para fertilizar os campos, os milagres de "fecundidade" foram os mais afamados. Como afirma Joaquim Manuel Ferreira Boiça:

«Os prodígios reconhecidos a S. Barão eram muitos e variados. À sua imagem dirigiamse padecentes de mil infortúnios, particularmente na sexta-feira de Ramos e no dia nove de Agosto, ocasiões em que se realizavam grandes romarias reunindo gentes oriundas das paróquias de Mértola e de muitas outras dos concelhos vizinhos. Houve quem, presenciando as festividades em sua honra, declarasse não haver «moléstia alguma que este Santo nam cure» embora fosse no «soldar quebrados e fecundar os casados» que os seus poderes mais se solicitavam». ${ }^{14}$

Pelos aspectos referidos, pode verificar-se que Mértola - um espaço lendário e místico - é um dos símbolos da continuidade de diversos cultos, desde a época pré-romana até à época cristã. Mértola, com os seus vestígios arqueológicos, com as suas lendas, com a presença do sufi Al-Mîrtulî e de S. Barão, incluindo o forte enraizamento do culto mariano, é prova do sincretismo religioso operado ao longo dos séculos. Tal como afirmou Teófilo Braga, «o cristianismo foi o resultado de uma transformação metafísica da tradição religiosa, sendo apenas o sincretismo informe de todos os elementos proselíticos que o precederam». ${ }^{15}$

Em conclusão, Mírtilis, Mirtolah, Mértola - terra de Romanos, de Árabes e de Cristãos - foi um espaço sacralizado e partilhado por diversas culturas, onde se cultuaram divindades pagãs (Prosérpina, Cíbele, Dioniso) e cristãs (os santos e a Virgem), onde "nasceram" lendas de mouras encantadas (a mulher serpente) e viveram os místicos Al-Mîrtulî e S. Barão, exemplos máximos do carácter lendário e místico da vila.

\section{Bibliografia}

AL-MÎRTULî (31998), "Quanto do que intento que não faço", in Adalberto Alves (trad.), O теи Coração é Árabe. Lisboa, Assírio \& Alvim.

(31998) "Não desprezas tuas vestes", in Adalberto Alves (trad.), $O$ meu Coração é Árabe. Lisboa, Assírio \& Alvim.

BOIÇA, Joaquim Manuel Ferreira (1998), Imaginária de Mértola - tempos, espaços e representações. s/l, edição co-financiada pela Comunidade Europeia FEDER/ PORA, Comissão de Coordenação da Região Alentejo, Campo Arqueológico de Mértola.

BRAGA, Teófilo (2000), Poesia do Direito - Raizes Poéticas do Cristianismo Lendas Cristãs. Lisboa, Imprensa Nacional - Casa da Moeda, col.«Pensamento

\footnotetext{
${ }^{14}$ Boiça 1998141.

${ }^{15}$ Braga 2000138.
} 
Português».

CABRAL, João, "Serpínia, a Princesa Feliz”, Arquivos de Serpa, 165-167, in http:// joraga.net/mertola/pags/20lendas1.htm\#serpinea

CHEVALIER, Jean; GHEERBRANT, Alain (1994), Dicionário dos Símbolos. Trad. de Cristina Rodrigues e Artur Guerra. Lisboa, Teorema.

FRAZÃO, Fernanda (s/d), Lendas Portuguesas, vol. 5. Lisboa, Amigos do Livro Editores, 89-90.

LEMAIRE, Ria (1999-2001), "Mélusine - Melusina / Mélusines - Melusinas: serpentes, sereias e dragões", Revista Lusitana, Nova Série, 19-21. Centro de Tradições Populares Portuguesas "Professor Manuel Viegas Guerreiro". Universidade de Lisboa, Faculdade de Letras, 81-107.

PALAZÁN, Juan Manuel Abascal (2002), "Ataecina”, in J. C. Ribeiro (coord.), Religiões da Lusitânia - Loquuntur Saxa. Lisboa, Museu Nacional de Arqueologia, 53-60.

PONTE, Maria de la Salete da (2002), "Amuletos na Província da Lusitânia”, in J. C. Ribeiro (coord.), Religiões da Lusitânia - Loquuntur Saxa. Lisboa, Museu Nacional de Arqueologia, 269-272.

SOURDEL, Dominique (21991), O Islão. Trad. de Mariana Quintela. Mem Martins, Publicações Europa-América, col. «Saber».

SOUZA, Vasco de (2002), "Escultura e Religião na Lusitânia" in J. C. Ribeiro (coord.), Religiões da Lusitânia - Loquuntur Saxa. Lisboa, Museu Nacional de Arqueologia, 247-250.

S. TOMÁS, Frei Leão de (1644), Beneditina Lusitana, Tomo I, Cap. VII. Coimbra, Officina de Diogo de Loureiro, 438-439. 